\title{
Classification of Safou (Dacryodes edulis) fruit size and shape on mass and outer dimensions
}

\author{
A. S. Ondo-Azi ${ }^{1 *}$ C. Ella Missang ${ }^{1,2}$ P. Nguema Ndoutoumou ${ }^{1}$, Th. Silou ${ }^{3}$ \\ ' (Département Phyotechnologie, Institut National Supérieur d'Agronomie et de Biotechnologies/ Université des \\ Sciences et Techniques de Masuku, Gabon) \\ ${ }^{2}$ (Institut de Recherche Technologique, Centre National de Recherche Scientifique et Technologique, Gabon) \\ ${ }^{3}$ (Pôle d'Excellence Régional AUF, Equipe Pluridisciplinaire de Recherche en Alimentation et Nutrition/ \\ Université Marien NGOUABI, Congo)
}

\begin{abstract}
Fruit size and shape are important quality parameters for product appreciation by consumers. However, aspect ratio (width over length) was used to perform the choice of ratios for fruits shape determination and mass for fruit category. This study was carried to quantitative classify Safou size and shape in bush butter (Dacryodes edulis (G. Don) H.J. Lam) fruits using fruit mass, as well as outer length and width measurements (aspect ratio). Results obtained showed that mass and aspect ratio can be used to classify Safou fruit size (small, medium and large) and shape (ellipsoidal, Obovate and spheroidal), respectively.Medium-sized fruits were the most represented. Irrespective of thefruit size, the ellipsoidal shape was most frequent and spheroidal shape was mostly found amongst small fruits and not amongst large fruits.
\end{abstract}

Keywords: Aspect ratio, Dacryodes edulis, Mass, Outer dimensions, Shape

\section{Introduction}

The Safou tree (Dacryodes edulis (G.Don) H.J. Lam, a tropical and subtropical tree belonging to the Burseraceae family, is an important native resource of the Gulf of Guinea. Indeed, consumer-preferences accelerated its spread from the Congo Basin to other parts of the world. Its pulp, the only edible part of the fruit, is rich in lipids, proteins, carbohydrates, minerals, vitamins and fibres [1-3].

Morphological characteristics of its fruits, studied on large scale samples from Cameroon, Gabon and Nigeria, present a broad variability [4-6]. Similar studies in Nigeria and later in the Congo [7-8], led to the classification of Safou fruits with respect to their masses into three main categories (small, medium and large). The values produced were $<20 \mathrm{~g}, 20-40 \mathrm{~g}$ and $>40 \mathrm{~g}$, and $<30 \mathrm{~g}, 30-70 \mathrm{~g}$ and $>70 \mathrm{~g}$ for Nigeria and Congo, respectively. Other related study described three shapes for Safou fruits from Gabon [9] while others define, similar to other fruits, Safou size and shape as the most important consumer-preferred quality parameters [1011]. The importance of such studies lies in the fact that they could contribute to the characterization of the fruit and further serve as guides to consumers and the food industry. In fact, physical characteristics of agricultural materials and their relationships are necessary for the design of some postharvest processing systems. Among these properties, the dimensions, mass, volume and projected area are the most important in the design of any grading system [12-14].

The aim of this study was to compare the size and shape of Safou fruits, based on mass and outer dimensions, in a bid to developing some objective and reproducible indicators for the characterization of the fruits that could be incorporated in strategies for industrial production of the fruit.

\subsection{Sampling of bush butter}

\section{Materials And Methods}

Ninety four (94) Safou trees (bush butter) were identified in farmers' fields across the different localities of Franceville city in Southeast Gabon. Mature fruits were then harvested from the four cardinal directions of each tree, above and under shade, placed in perforated sacks and transported to the laboratory. There, all damaged fruits were discarded and twenty fruits were maintained from each tree for eventual characterization.

\subsection{Morphological and physical measurements}

The mass of each fruit was determined using a precision balance $(e=0.1 \mathrm{mg})$ and its dimensional measurements (length and width) taken using a pair of callipers (precision $\approx 0.1 \mathrm{~mm}$. The aspect ratio was computed as the ratio of the width (shorter dimension) to the length (longer dimension). The Safou fruits were separated by mass in accordance with established methods [8] that classify them into three main categories : small, average and large. 


\subsection{Shape detection}

A technique was adopted for the determination of the fruits' shape, based on an analysis of its outer dimensions. The aspect ratio was computed using equation 1 described elsewhere [5]. The parameters D1, D2 and D3 represent elliptical, obovate and spheroidal-shaped fruits, respectively while ' $R$ ' was the aspect ratio ((1), (2) and (3)). Descriptive and other statistical data analyses were conducted using Microsoft Excel software and its variate, the Xlstat 2011 was used.

\section{Results And Discussion}

Morphological and physical characteristics of $D$. edulis collected from Franceville showed that the average fruit length, fruit width and fruit mass were $6 \mathrm{~cm}, 3.3 \mathrm{~cm}$, and 3,803 g, respectively (Table 1). However, considerable morphological differences were observed among the trees and for each of these parameters as the coefficients of variation ranged from a minimum $12 \%$ for fruit width $35 \%$ for fruit mass. The width/length ratio (W/L) ranged from 0.29 to 0.92 , with a mean of 0.57 . These values are similar to previously obtained figures for Gabon and the Congo [15] and were equally in agreement with previous results obtained in areas renowned for bush butter production $[5,6,16]$.

The masses of the small-sized Safou fruits (less than $30 \mathrm{~g}$ ), medium-sized fruits (30 - $45 \mathrm{~g}$ ) and largesized fruits (more the $85 \mathrm{~g}$ ) varied considerably as could be seen in Figure 2. Medium-sized fruits constituted the most important Safou class, representing almost half $(43 \%)$ of sampled trees in the study. These results are in conformity with those obtained in a previous survey on 227 Safou trees in Gabon [6]. Analysis of Safou fruit mass and outer dimensions (length and width) showed that the fruits could be categorised in three shapes and three sizes, giving a total of nine "size x shape" combinations (Fig. 1). The frequency of medium Safous was highest (48\%) amongst the three sizes, while those of the large and small fruits were least (24-28\%) as shown in Table 3. With regards to their shapes and on the whole, the frequency of ellipsoidal-shaped Safous was highest (51\%). The large-sized category did not have fruits of spheroidal shape, whereas small and mediumsized fruits had equal proportions of spheroidal-shaped fruits. These observations conform to those presented by stakeholders in the Safou commodity chain, confirming thereby the recently recorded "fruit shape $\mathrm{x}$ fruit dimension" interaction [17] where small calibre fruits had shapes that contrasted with those of the other calibres.

\section{Indentations and EQUATIONS}

Equation 1, Equation 2 Equation 2 $\begin{array}{ll}\text { Elliptical: } & \mathrm{D}_{1}=|\mathrm{R}-0.52|(1) \\ \text { Obovate: } & \mathrm{D}_{2}=|\mathrm{R}-0.60|(2) ; \\ \text { Spheroidal: } & \mathrm{D}_{3}=|\mathrm{R}-0.68|(3) .\end{array}$

\section{Figures and Tables}

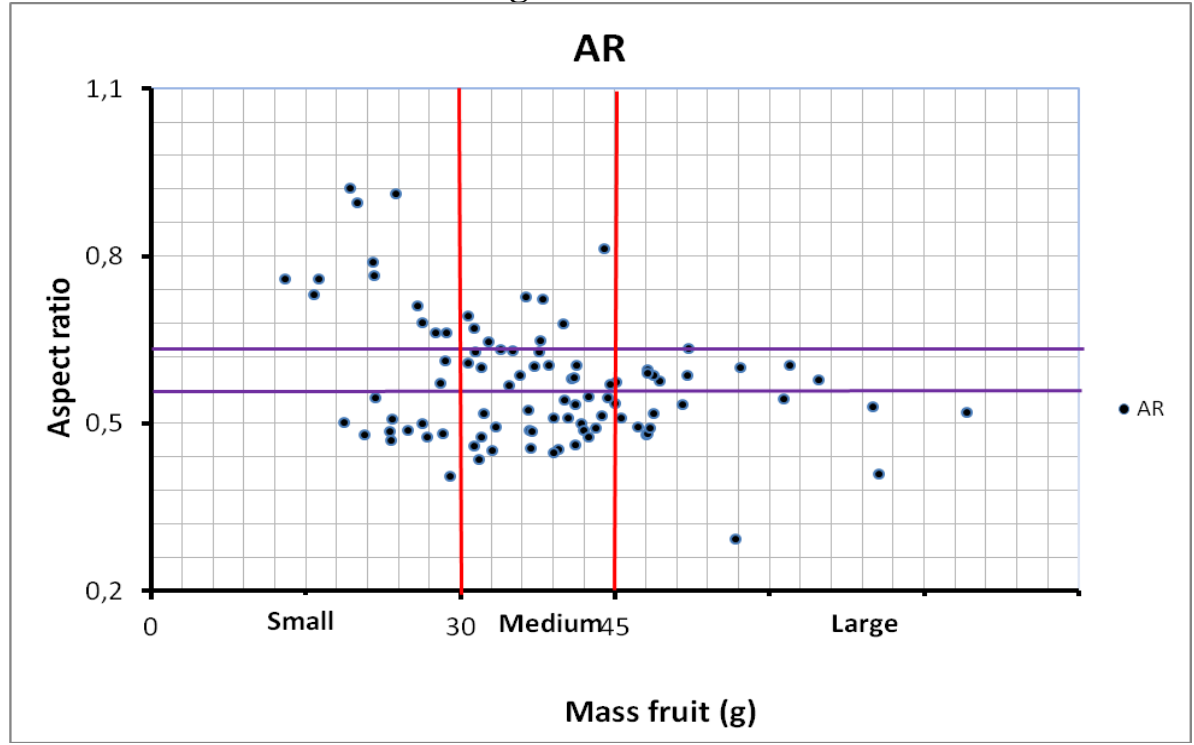

Figure 1. Aspect ratio versus mass representation

Fig. 1. Aspect ratio versus mass representation

AR: Aspect ratio

Classes Large, Medium and Small correspond to repartition obtained by using fruit mass 
Table 1. Statistic description of all Safou fruits $n=1,880$

\begin{tabular}{|l|c|c|c|c|}
\hline & Length $(\mathrm{cm})$ & Width $(\mathrm{cm})$ & Mass $(\mathrm{g})$ & Aspect ratio \\
\hline Arithmetic mean & 6.01 & 3.34 & 38.29 & 0.57 \\
\hline Variance & 1.41 & 0.15 & 182.02 & 0.01 \\
\hline Median & 6.12 & 3.32 & 37.42 & 0.56 \\
\hline Standard deviation & 1.19 & 0.39 & 13.49 & 0.11 \\
\hline Coefficient of variation & 19.7 & 11.70 & 35.10 & 18.9 \\
\hline Minimum & 3.35 & 2.50 & 12.94 & 0.29 \\
\hline Maximum & 11.10 & 4.46 & 89.49 & 0.92 \\
\hline
\end{tabular}

Table 1. Statistic description of the 1880 fruits collected from 94 Safou trees

With $n=20$ fruits from each tree

Table 2. Classification of Safou trees according to fruit mass

\begin{tabular}{|l|c|c|c|}
\hline \multicolumn{1}{|c|}{ Size } & Mass range $(\mathrm{g})$ & Population & Frequency $(\%)$ \\
\hline Small & $<30$ & 25 & 26.6 \\
\hline Medium & $30-45$ & 46 & 48.9 \\
\hline Large & $>45$ & 23 & 24.4 \\
\hline
\end{tabular}

Table 2. Safou trees reparations according fruit mass

Classes Large, Medium and Small correspond to repartition obtained by using fruit mass

Table 3. Classification of selected Safou fruits from Franceville Gabon with respect to mass, shape and aspect ratio

$\left.\begin{array}{|l|l|l|l|l|l|}\hline \text { Size } & \text { Mass range (g) } & \text { Shape } & \text { Aspect ratio range } & \text { Frequency (\%) } \\ \hline \text { Small } & <30 & \text { Ellipsoidal } & 0.41-0.55 & 11.7 & \multicolumn{2}{|c|}{\mathbf{2 6 . 6}} \\ \hline & & \text { Obovate } & 0.57-0.61 & 2.1 & 12.8\end{array}\right\}$

Table 3. Size, mass range, aspect ratio range and frequency of the randomly of the 94 selected Safou fruits collected in Franceville Gabon

\section{Conclusion}

Fruit mass and outer dimensions (length and width) as well as their ratios appear quite suitable as parameters for the characterisation and morphological classification of Safou fruits as they lead to the generation of objective and reproducible results, with the ellipsoidal and medium-sized fruits being the most represented. Such results which could therefore be incorporated in strategies for industrial production of Safou, could equally be adapted and applied to other products.

\section{Acknowledgements}

This work was supported by the "Agence Universitaire de la Francophonie (AUF)" and Agrifood process engineering (GP3A) network.

\section{References}

[1] U. Omoti, and D.A. Okiy, Characteristics and composition of the pulp oil and cake of the African pear, Dacryodes edulis (G.Don) H.J. Lam, Journal of the Science of Food and Agriculture 38, 1987, 67-72. 
[2] T. Silou, Le safoutier (Dacryodes edulis) un arbre mal connu. Fruits 51, 1996,47-60.

[3] E. Youmbi, M. Mbeuyo, N.D. Tchinda, and A. Amougou, Physico-chemical characterization and classification of fruits of Dacryodes edulis from the major agro-ecological zones of Cameroon. Fruits 66(6), 2010, 355-365.

[4] A.N. Waruhiu, J. Kengue, A.R. Atangana, Z. Tchoundjeu, and RRB Leakey, Domestication of Dacryodes edulis: 2. Phenotypic variation of fruit traits in 200 trees from four populations in the humid lowlands of Cameroon. Food, Agriculture \& Environment 2, 2004, 340-346.

[5] P.O. Anegbeh, V. Ukafor, C. Usoro, Z. Tchoundjeu, RRB Leakey and K. Schreckenberg, Domestication of Dacryodes edulis: 1. Phenotypic variation of fruit traits from 100 trees in southeast Nigeria. New Forests 29, 2004, 149-160.

[6] A.S. Ondo-Azi, C. Ella Missang, and T. Silou, Classification of Dacryodes edulis (G. Don) H.J. Lam by using morphological and physical characteristics of the fruits: a statistical approach. Forests, Trees and Livelihoods 19, 2009, 99-109.

[7] H.A. Okorie, and T.O.C. Ndubizu, Interspecific variation in fruit and vegetative characters in African Pear (Dacryodes edulis (G. Don) H.J. Lam), Proc 12 ${ }^{\text {th }}$ Annual Conference of the Horticultural Society of Nigeria, Nsukka, Nigeria, $3-6^{\text {th }}$ November 1991.

[8] T. Silou, G. Rocquelin, G. Gallon, and T. Molagui, Contribution à la caractérisation des safous (Dacryodes edulis) d'Afrique Centrale. Note II- Composition chimique et caractéristiques nutritionnelles des safous du district de Boko (Congo-Brazzaville). Variation inter-arbre, Rivista Italiana delle Sostanze Grasse 77, 2000, 85-89.

[9] A.S. Ondo-Azi, C. Ella Missang, P. Nguema Ndoutoumou, and T. Silou,. Analysing fruit shape in safou (Dacryodes edulis) fruit by using aspect ratio, International Journal of Agronomy and Agricultural Research 3, 2013, 7-12.

[10] M. Rashidi, and K. Seyfi, Classification of fruit shape in cantaloupe using the analysis of geometrical attributes, World Applied Sciences Journal 3, 2007, 735-740.

[11] M. Rashidi, and M. Gholami, Classification of fruit shape in kiwifruit using the analysis of geometrical attributes. AmericanEurasian Journal of Agricultural and Environmental Sciences 3, 2008, 258-263.

[12] M.A. Safwat, Theoretical prediction of volume, surface area, and center of gravity for agricultural products. Transactions of the ASAE 14, 1971, 549-553.

[13] N.N. Mohsenin, Physical properties of food and agricultural materials (Gordon, Branch, 1986).

[14] E. Seyedabadi, M. Khojastehpour, H. Sadrnia, and M.H. Saiedirad, Mass modeling of cantaloupe based on geometric attributes: A case study for Tile Magasi and Tile Shahri. Scientia Horticulturae 130, 2011, 54-59.

[15] R. Kama-Niamayoua, Valorisation alimentaire du safou (Dacryodes edulis). Quantification et caractérisation de la matière première, évaluation des potentialités technologiques en vue de la production d'huile, doctoral diss., Université Marien NGOUABI, Brazzaville, Congo, 2006.

[16] T. Silou, G. Rocquelin, I. Mouaragagja, G. Gallon, Chemical composition and nutritional characteristics of bush butter (Dacyodes edulis) of Cameroon and the Congo-Brazzaville, the Congo-Kinshasa and Gabon. Rivista Italiana delle sostanze Grasse 79, 2002, $177-182$.

[17] R.N. Poligui, I. Mouaragadja, E. Haubruge, and F. Francis, La culture du safoutier (Dacryodes edulis [G.Don] H.J.Lam [Burseraceae]) : enjeux et perspectives de valorisation au Gabon (synthèse bibliographique), Biotechnologies Agronomie Société Environnement 17(1), 2013, 131-147. 